\title{
Biplane transrectal ultrasonography plus ultrasonic elastosonography and contrast- enhanced ultrasonography in T staging of rectal cancer
}

Yanru Feng ${ }^{1,2,3 \dagger}$, Chanjuan Peng ${ }^{1,4,5^{\dagger}}$, Yuan Zhu $u^{1,2,3}$ and Luying Liu Li, $^{1,23^{*}}$ (1)

\begin{abstract}
Background: The aim of this study is to assess biplane transrectal ultrasonography (TRUS) plus ultrasonic elastosonography (UE) and contrast-enhanced ultrasonography (CEUS) in T staging of rectal cancer.

Methods: Between March 2016 and January 2019, 66 rectal cancer patients who completed biplane TRUS plus UE and CEUS for preoperative workup and were treated by primary total mesorectal excision (TME) were retrospectively analyzed.

Results: The accuracy of TRUS plus UE and CEUS in all T staging of rectal cancer was $69.7 \%$. The highest accuracy was achieved in the T3 stage (87.5\%), while it was 71.4 and $50.0 \%$ in the $\mathrm{T} 1$ and $\mathrm{T} 2$ stage, respectively. The mean sizes of UT1-T2 lesions and UT3-T4 lesions were $30.0 \pm 10.6 \mathrm{~mm}$ (range, 10.0-55.0) and 40.2 $\pm 11.2 \mathrm{~mm}$ (range, 14.0$57.0)$, respectively $(p<0.001)$. According to the receiver operating characteristic $(R O C)$ curve to predict pT stages (pT1,2 vs. pT3), the optimal cut-off value of lesions in greatest dimension was $28.5 \mathrm{~mm}$ by TRUS with areas under the curve (AUC) of 0.769 , and the optimal cut-off values of peak systolic velocity (PSV) and resistive index (RI) were $18.8 \mathrm{~cm} / \mathrm{sec}$ and 0.645 , respectively. The AUCS of PSV and RI were 0.588 and 0.555 , respectively.

Conclusions: Diagnostic accuracy of TRUS plus UE and CEUS in T staging of rectal cancer does not reach the excellent published study results, especially for patients with early rectal cancer. Tumor sizes, PSV and RI are useful additions for TRUS in T staging of rectal cancer.
\end{abstract}

Keywords: Biplane transrectal ultrasonography, Ultrasonic elastosonography, Contrast-enhanced ultrasonography, Rectal cancer

\footnotetext{
*Correspondence: liuly@zjcc.org.cn

†Yanru Feng and Chanjuan Peng contributed equally to this work.

${ }^{1}$ Institute of Cancer Research and Basic Medicine (ICBM), Chinese Academy of Sciences, No 1, East Banshan Road, Gongshu District, Hangzhou 310022, China

${ }^{2}$ Department of Radiation Oncology, Cancer Hospital of the University of Chinese Academy of Sciences, No 1, East Banshan Road, Gongshu District, Hangzhou 310022, China

Full list of author information is available at the end of the article
}

(c) The Author(s). 2020 Open Access This article is licensed under a Creative Commons Attribution 4.0 International License, which permits use, sharing, adaptation, distribution and reproduction in any medium or format, as long as you give appropriate credit to the original author(s) and the source, provide a link to the Creative Commons licence, and indicate if changes were made. The images or other third party material in this article are included in the article's Creative Commons licence, unless indicated otherwise in a credit line to the material. If material is not included in the article's Creative Commons licence and your intended use is not permitted by statutory regulation or exceeds the permitted use, you will need to obtain permission directly from the copyright holder. To view a copy of this licence, visit http://creativecommons.org/licenses/by/4.0/ The Creative Commons Public Domain Dedication waiver (http://creativecommons.org/publicdomain/zero/1.0/) applies to the data made available in this article, unless otherwise stated in a credit line to the data. 


\section{Background}

Worldwide, colorectal cancer is the third most commonly diagnosed cancer and rectal cancer accounts for approximately one third of these cases [1]. Accurate staging is critical for rectal cancer to select appropriate therapy. In the National Comprehensive Cancer Network (NCCN) guidelines for rectal cancer, endorectal ultrasound (EUS) was suggestted when magnetic resonance imaging (MRI) was contraindicated or considered for superficial lesions [2]. Recently, a metaanalysis of comparing the diagnostic accuracy of EUS and MRI in the staging of rectal cancer indicated that EUS was superior to MRI in overall $\mathrm{T}$ staging [3].

In 1991, Ophir J et al. first described ultrasonic elastosonography (UE) [4]. UE is an imaging technology of strain and elastic modulus distributions in soft tissues and has been widely applicated in the liver, kidney, prostate, breast, thyroid and so on [5]. Contrast-enhanced ultrasonography (CEUS) is a technique of depicting microvessels and parenchymal perfusion with the use of specific contrast agents [6]. CEUS is complementary to ultrasonography-guided fine-needle aspiration for diagnosis, staging, and predicting treatment response [7]. However, the role of UE and CEUS for rectal cancer is limited [8-10]. The aim of this study is to assess biplane transrectal ultrasonography (TRUS) plus UE and CEUS in $\mathrm{T}$ staging of rectal cancer.

\section{Methods}

\section{Patients}

After obtaining approval from our institutional review board, rectal cancer patients $(n=69)$ who completed biplane TRUS plus UE and CEUS for preoperative workup and were treated by primary total mesorectal excision (TME) between March 2016 and January 2019 were retrospectively analyzed. Of these 69 patients, 3 were excluded from the present analysis for endoscopic submucosal dissection before TME $(n=1)$, neuroendocrine tumor $(n=1)$, and incompletion of TRUS for large tumor $(n=1)$. The present study included the remaining 66 patients. tThere were 16 female and 50 male patients with an age range of 24 to 84 years (median age, 61.5 years). The median distance from anal verge of lesion was $4.9(0-10) \mathrm{cm}$. The median time between TRUS plus UE and CEUS testing and TME was 5 (rang, 0-40) days.

\section{Patient preparation prior to TRUS plus UE and CEUS}

The cleaning enema was performed $1 \mathrm{~h}$ before examination. The Sims' position was used and digital examination of rectum was performed to obtain the preliminary assessments of the lesion.

\section{TRUS plus UE and CEUS protocol}

An Ecodoppler Color Esaote MyLab ${ }^{\text {tw }}$ ClassC ultrasound system (Esaote, Genoa, Italy) was used, along with the

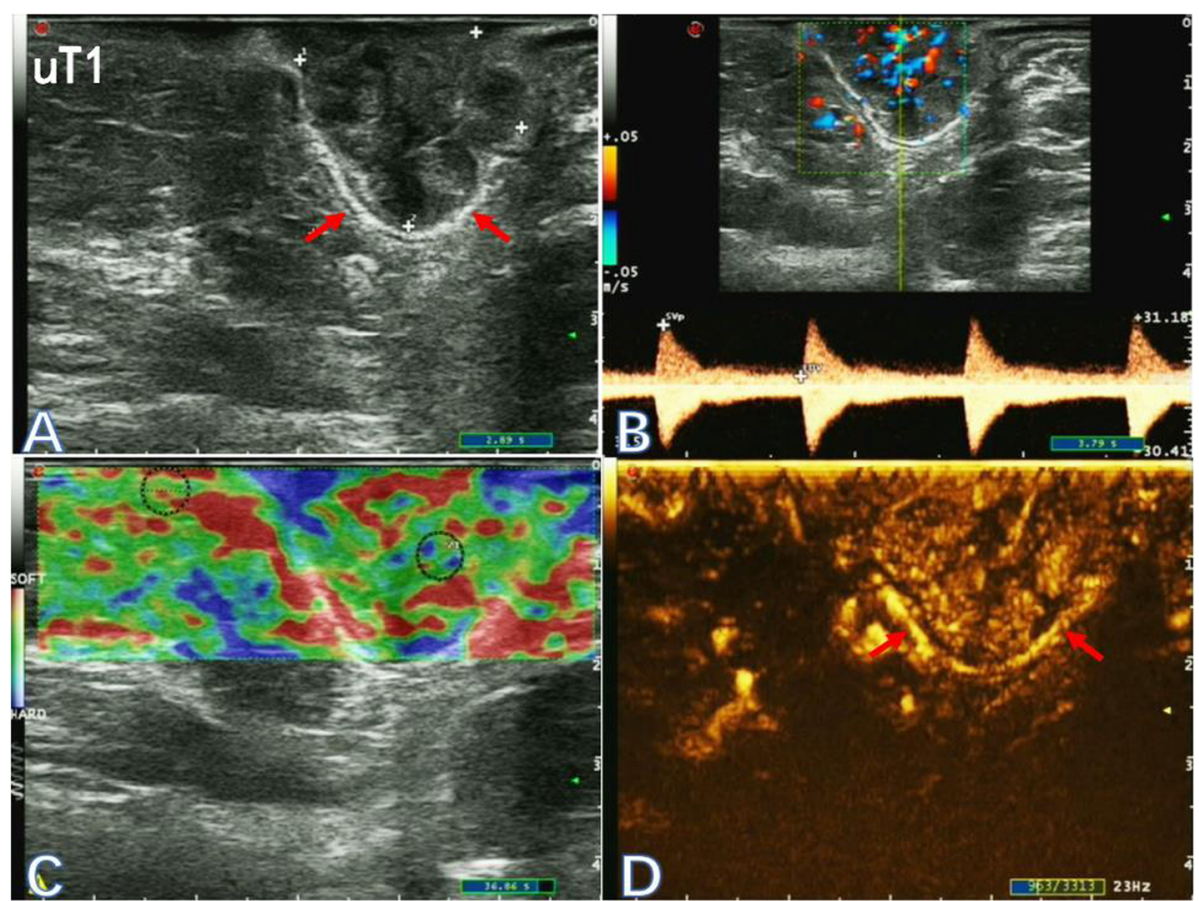

Fig. 1 Two-dimensional ultrasonogram (a), color-flow and pulsed Doppler image (b), elastogram (c) and the corresponding contrast-enhanced ultrasonogram (d) of a 45-year-old male patient with stage uT1 low rectal cancer (red arrow) 


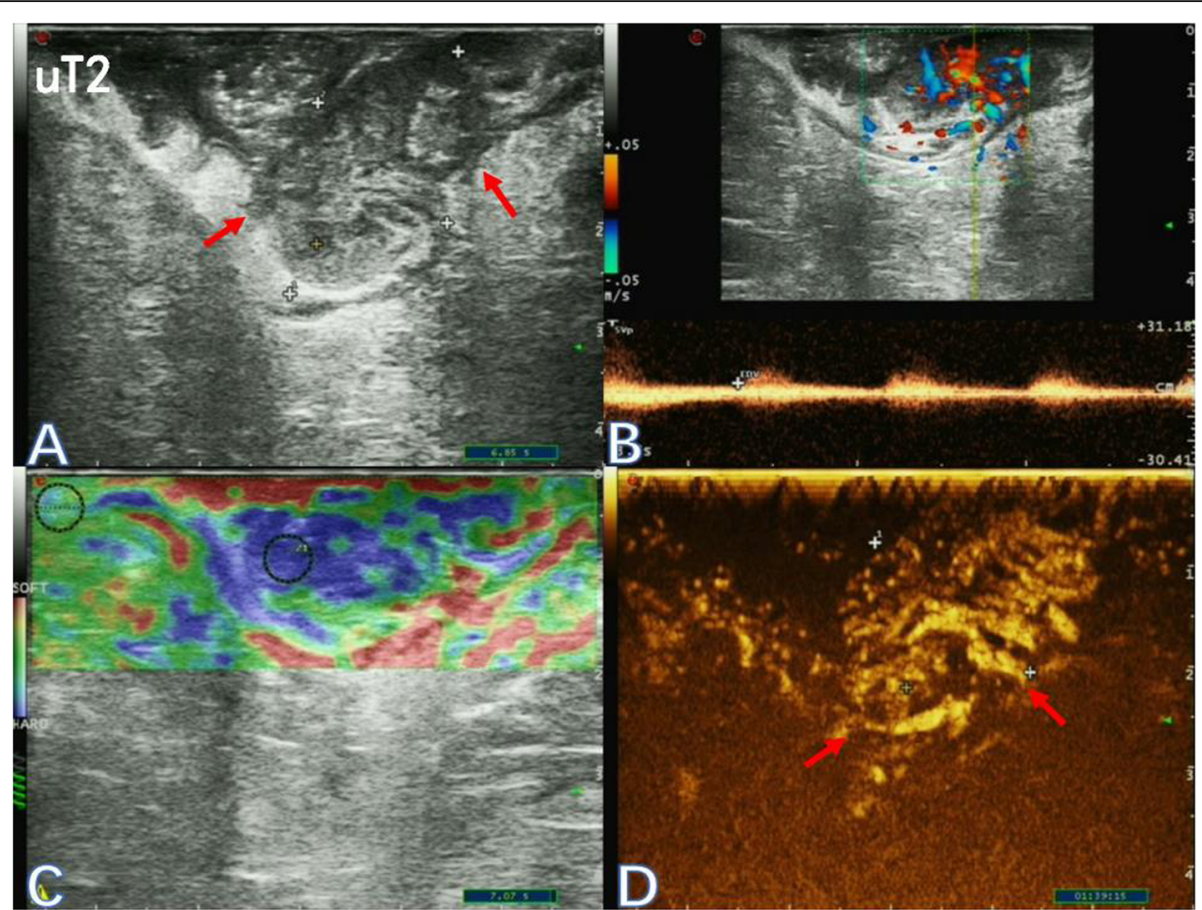

Fig. 2 Two-dimensional ultrasonogram (a), color-flow and pulsed Doppler image (b), elastogram (c) and the corresponding contrast-enhanced ultrasonogram (d) of a 69-year-old female patient with stage uT2 low rectal cancer (red arrow)

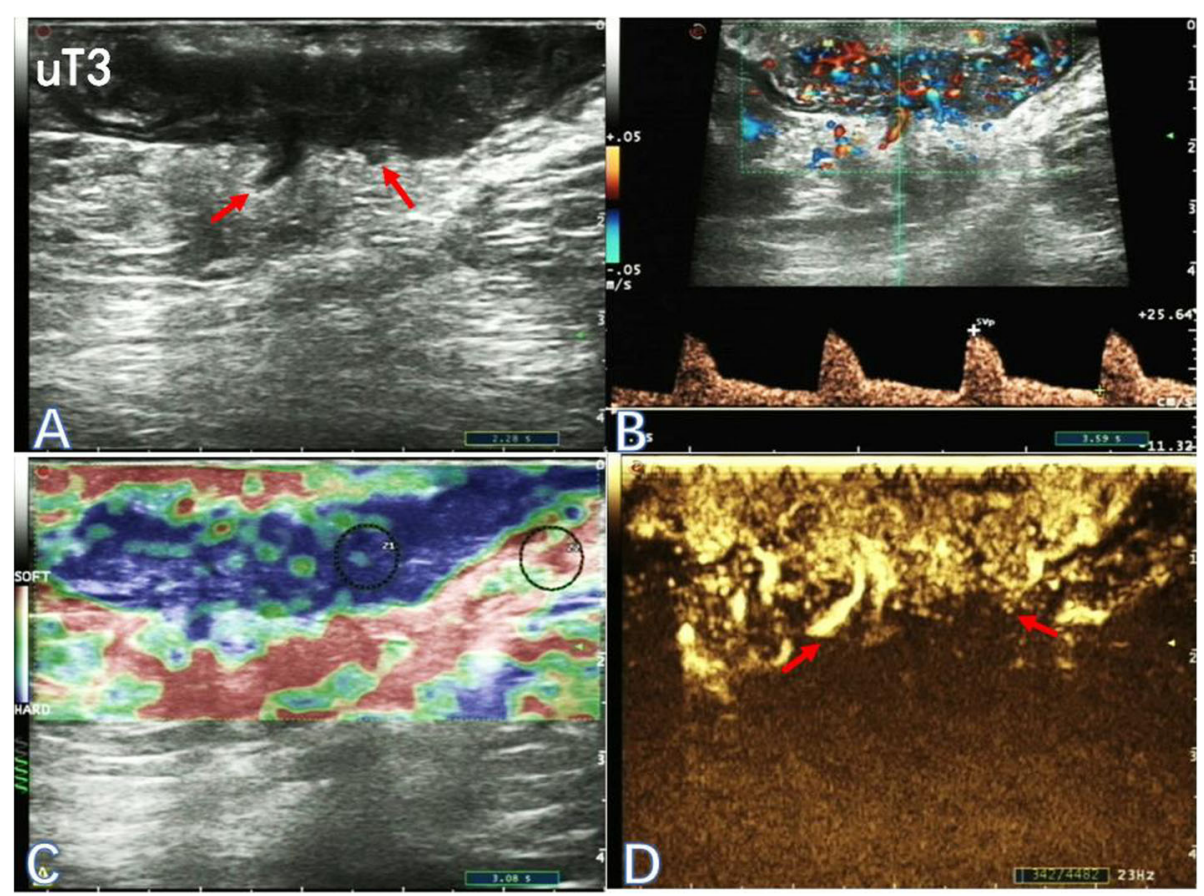

Fig. 3 Two-dimensional ultrasonogram (a), color-flow and pulsed Doppler image (b), elastogram (c) and the corresponding contrast-enhanced ultrasonogram (d) of a 61-year-old male patient with stage uT3 low rectal cancer (red arrow) 
TRT33 Transrectal Biplane Transducer (Esaote). Sulphur hexafluoride (SF6) lipid-coated microbubble contrast agent SonoVue $^{\mathrm{mi}}$ (Bracco SpA, Milan, Italy) was used for CEUS. The methods of TRUS plus UE and CEUS were described previously [10]. Based on two-dimensional ultrasonograms, color Doppler ultrasound images, elastograms and CEUS image data, ultrasonic $\mathrm{T}$ classification was diagnosed for rectal cancer (Figs. 1, 2 and 3). The staging criteria by Beynon et al. [11] was adopted for ultrasonic staging and the 8th edition of the American Joint Committee on Cancer (AJCC) staging system was adopted for pathological staging. Furthemore, the primary tumor was assessed in three planes and the largest diameter was noted.

\section{Statistical analyses}

Statistical analysis was carried out using SPSS version 22.0 (IBM, Armonk, NY, USA). Data were expressed as means \pm standard deviation (SD). The predictive abilities of size of lesion, peak systolic velocity (PSV) and resistive index (RI) for pT classification (pT1,2 vs. pT3) were calculated by the receiver operating characteristic (ROC) curves. The differences between the parameters (PSV, RI and size) and pT classification (pT1,2 vs. pT3) were calculated by Chi-square and Student's t tests. Statistical tests were based on a two-sided significance level. $p<$ 0.05 indicated statistical significance.

\section{Results}

\section{Biplane TRUS plus UE and CEUS in pT stages of rectal cancer}

According to the 8th AJCC staging system, the pT stage distribution for all patients was $18.2 \%$ Stage pT1 $(n=$ 12), $24.2 \%$ Stage pT2 $(n=16)$, and $57.6 \%$ Stage pT3 $(n=$ 38). By biplane TRUS plus UE and CEUS, 7 (10.6\%), 26 (39.4\%), $32(48.5 \%)$, and 1 (1.5\%) patients were classified as stage uT1, stage uT2, stage uT3, and stage uT4, respectively. Of these, 46 (69.7\%) patients were diagnosed with correct ultrasonic $\mathrm{T}$ staging. The details are shown in Tables 1 and 2.

\section{Size of lesion}

The mean sizes of uT1-T2 lesions and uT3-T4 lesions were $30.0 \pm 10.6 \mathrm{~mm}$ (range, 10.0-55.0) and $40.2 \pm 11.2$ mm (range, 14.0-57.0), respectively $(p<0.001)$. According to the ROC curve to predict $\mathrm{pT}$ stages (pT1,2 vs. pT3), the optimal cut-off value of lesions in greatest dimension was $28.5 \mathrm{~mm}$ by TRUS with areas under the curve (AUCs) of 0.769. The mean sizes of pT1-T2 lesions and $\mathrm{pT} 3$ lesions were $33.5 \pm 18.4 \mathrm{~mm}$ (range, 6.0-90.0) and $41.4 \pm 12.2 \mathrm{~mm}$ (range, 13.0-80.0), respectively $(p=0.045)$. No significant difference was observed in terms of size between $\mathrm{uT}$ lesions and $\mathrm{pT}$ lesions $(p=0.184)$.

\section{Color-flow imaging and pulsed Doppler sonography of lesions}

The mean PSV and RI were $17.5 \pm 6.1 \mathrm{~cm} / \mathrm{sec}$ (range, 8.3-36.0) and 0.74 \pm 0.09 (range, 0.47-0.90), respectively. The mean PSV of pT1, pT2 and pT3 was $19.9 \pm 7.2 \mathrm{~cm} /$ sec (range, 9.0-31.2), $17.4 \pm 5.6 \mathrm{~cm} / \mathrm{sec}$ (range, 8.3-29.3), and $16.8 \pm 5.9 \mathrm{~cm} / \mathrm{sec}$ (range, 9.0-36.0), respectively. The mean RI of pT1, pT2 and pT3 was $0.72 \pm 0.07$ (range, $0.65-0.85$ ), $0.78 \pm 0.06$ (range, 0.67-0.86), and $0.73 \pm$ 0.11 (range, 0.47-0.90), respectively. According to the ROC curve to predict pT stages (pT1,2 vs. pT3), the optimal cut-off values of PSV and RI were $18.8 \mathrm{~cm} / \mathrm{sec}$ and 0.645 , respectively. The AUCs of PSV and RI were 0.588 and 0.555 , respectively. A marginal significant difference was observed in terms of $\mathrm{pT}$ stages between the PSV > $18.8 \mathrm{~cm} / \mathrm{sec}$ and $\leq 18.8 \mathrm{~cm} / \mathrm{sec}$ groups $(p=0.057)$. Significant difference was observed in terms of $\mathrm{pT}$ stages between the $\mathrm{RI}>0.645$ and $\leq 0.645$ groups $(p=0.017)$.

\section{Discussion}

The accuracy of $\mathrm{T}$ staging is pivotal for patients with rectal cancer in deciding on a course of therapy. The accuracy of $\mathrm{T}$ staging of rectal cancers by EUS has varied considerably in the literature [12]. In the present study, the accuracy of TRUS plus UE and CEUS in all $\mathrm{T}$ stages of rectal cancer was $69.7 \%$. The highest accuracy was achieved in the T3 stage (87.5\%), while it was 71.4 and $50.0 \%$ in the $\mathrm{T} 1$ and $\mathrm{T} 2$ stage, respectively. In the "Real World" study based on UK transanal endoscopic microsurgery database, TRUS was performed in 165 patients with uT0-T3 rectal cancer and the accuracy of TRUS in all $\mathrm{T}$ stages was $55.2 \%$. The accuracy of T1, T2 and T3

Table 1 T staging of biplane TRUS plus UE and CEUS versus pathological T staging

\begin{tabular}{|c|c|c|c|c|c|c|c|c|}
\hline \multirow{2}{*}{$\begin{array}{l}\text { Ultrasonic } \\
\text { T stage }\end{array}$} & \multicolumn{4}{|c|}{ Pathological T stage (n) } & \multirow[t]{2}{*}{ Total } & \multicolumn{3}{|c|}{ Ultrasonic T staging [n (\%)] of patients } \\
\hline & pT1 & pT2 & pT3 & pT4 & & Overstaged & Understaged & Correctly staged \\
\hline uT1 & 5 & 0 & 2 & 0 & 7 & $0(0.0)$ & 2(28.6) & $5(71.4)$ \\
\hline uT2 & 6 & 13 & 7 & 0 & 26 & $6(23.1)$ & $7(26.9)$ & 13(50.0) \\
\hline uT3 & 1 & 3 & 28 & 0 & 32 & $0(0.0)$ & $4(12.5)$ & $28(87.5)$ \\
\hline uT4 & 0 & 0 & 1 & 0 & 1 & $1(100.0)$ & $0(0.0)$ & $0(0.0)$ \\
\hline Total & 12 & 16 & 38 & 0 & 66 & $7(10.6)$ & 13(19.7) & $46(69.7)$ \\
\hline
\end{tabular}

TRUS Transrectal ultrasonography, UE Ultrasonic elastosonography, CEUS Contrastenhanced ultrasonography 
Table 2 Sensitivity, specificity, positive and negative predictive values for T staging of biplane TRUS plus UE and CEUS

\begin{tabular}{lllll}
\hline Ultrasonic T stage & Sensitivity & Specificity & Positive predictive value & Negative predictive value \\
\hline UT1 & $41.7 \%(5 / 12)$ & $96.3 \%(52 / 54)$ & $71.4 \%(5 / 7)$ & $88.1 \%(52 / 59)$ \\
UT2 & $81.3 \%(13 / 16)$ & $74.0 \%(37 / 50)$ & $50.0 \%(13 / 26)$ & $92.5 \%(37 / 40)$ \\
UT3 & $73.7 \%(28 / 38)$ & $85.7 \%(24 / 28)$ & $87.5 \%(28 / 32)$ & $70.6 \%(24 / 34)$ \\
UT4 & $-(0 / 0)$ & $98.5 \%(65 / 66)$ & $0.0 \%(0 / 1)$ & $100.0 \%(65 / 65)$ \\
\hline
\end{tabular}

Note, the data in parentheses represent the ratio of the number of patients

TRUS Transrectal ultrasonography, UE Ultrasonic elastosonography, CEUS Contrastenhanced ultrasonography

lesions was $72.2 \%(52 / 72), 58.7 \%(27 / 46)$ and $68.8 \%(11 /$ $16)$, respectively [13]. In the prospective multicenter observational study of TRUS for local staging of rectal cancer, uT stage could be compared with pT stage in 3501 patients and the accuracy of TRUS in all $\mathrm{T}$ stages was $65.8 \%$. The accuracy of $\mathrm{T} 1, \mathrm{~T} 2$ and $\mathrm{T} 3$ lesions was $76.4 \%(307 / 402), 56.0 \%(676 / 1208)$ and $68.8 \%(1268 /$ 1780), respectively [14]. In another multicenter, prospective study, 7096 patients met the standards for a $\mathrm{uT}-\mathrm{pT}$ comparison and the $\mathrm{uT}-\mathrm{pT}$ correspondence was 64.7\%. In addition, the uT-pT correspondence was higher in hospitals with a case load of over 30 per year than those with less than 10 patients per year $(73.1 \%$ vs $63.2 \%$ ) [15]. However, the pooled sensitivity and specificity in T staging were 79 and $89 \%$ for TRUS in the diagnostic test accuracy meta-analysis including 234 patients [3]. The different accuracy of TRUS in T staging of rectal cancer may be explained by various factors, such as the experience of the diagnostician, previous biopsy and endoscopic manipulation, peritumour inflammatory or fibrotic response, the technological developments of ultrasound and so on [13].

For the technological developments of ultrasound, the $85 \%$ accuracy was achieved in study of combining grayscale sonography with color-flow imaging and pulsed Doppler transrectal sonography for the $\mathrm{T}$ staging of rectal cancer [16]. UE combined with TRUS could improve the staging of early rectal cancer [9] and CEUS was valuable for assessing microcirculation and the perfusion features of rectal cancer [8]. For patients with localized prostate cancer, multiparametric TRUS including grayscale imaging, color Doppler imaging, shear wave elastography, and contrast-enhanced ultrasound had higher sensitivity, negative predictive value, and accuracy than multiparametric MRI (97.4\% versus 94.7, 96.9\% versus 92.3 , and $87.2 \%$ versus $76.9 \%$, respectively) [17]. In the study including 108 patients with cervical cancer, CEUS was comparable to magnetic resonance imaging for measuring tumour size (left-right $r=0.84$, craniocaudal $r=0.86$ and anteroposterior $r=0.88$ ) [18]. The $84.9 \%$ accuracy was achieved in the previous study from our center using biplane TRUS plus UE and CEUS for T staging of locally advanced rectal cancer after neoadjuvant chemoradiotherapy [10]. In the present study, the $87.5 \%$ accuracy was achieved in the T3-stage using biplane TRUS plus UE and CEUS.

Heneghan et al. reported that the mean sizes of pT1-2 and pT3-4 lesions were $2.9 \pm 1.1 \mathrm{~cm}$ (range, 1.2-5) and $4.9 \pm 2.2 \mathrm{~cm}$ (range, $2.6-10)$, respectively $(p=0.0016)$. A lesion $\geq 4 \mathrm{~cm}$ in greatest dimension could be predictive for T3-T4 by ROC curve analysis [16]. In the present study, significant difference was observed in terms of the mean sizes between uT1-T2 lesions and uT3-T4 lesions. For improving the staging of TRUS, a lesion $28.5 \mathrm{~mm}$ in greatest dimension by TRUS could be predictive for pT3 by ROC curve analysis. Although tumor size has not been adopted for staging of rectal cancer to date, it is helpful in uncertainty for the depth of invasion during TRUS.

RI was decreased with the increase of $\mathrm{pT}$ staging and PSV was significantly increased with the increase of $\mathrm{pT}$ staging in the study including 56 rectal cancer patients receiving TRUS [19]. In Heneghan et al's study, significant difference was observed in terms of mean PSV between T1-T2 lesions $(19.3 \pm 9.2 \mathrm{~cm} / \mathrm{sec})$ and T3-T4 lesions $(31.5 \pm 16.3 \mathrm{~cm} / \mathrm{sec}) \quad(p=0.048)$. No significant difference was observed in terms of mean RI between T1-T2 lesions and T3-T4 lesions $(p=0.15)$ [16]. With respect to the results of PSV and RI in the present study, the association of PSV, RI and T staging should be evaluated in larger cohorts from muti-centre in the future.

There are several limitations in the current study, including the retrospective nature of the study design, a single center experience, and the limited number of patients, which could affect the outcomes. Nevertheless, our report is noteworthy because this is the first study to evaluate biplane TRUS plus UE and CEUS in T staging of rectal cancer after primary TME. Ultrasonography based radiomics has been used to improve prediction of lymph node metastasis of rectal cancer [20]. The role of UE and CEUS based radiomics for rectal cancer should be elucidated in the future.

\section{Conclusions}

Diagnostic accuracy of TRUS plus UE and CEUS in $\mathrm{T}$ staging of rectal cancer does not reach the excellent published study results, especially for patients with early rectal cancer. Tumor sizes, PSV and RI are useful additions for TRUS in T staging of rectal cancer. 


\section{Abbreviations}

TRUS: Transrectal ultrasonography; UE: Ultrasonic elastosonography; CEUS: Contrast-enhanced ultrasonography; TME: Total mesorectal excision; ROC: Receiver operating characteristic; AUC: Areas under the curve; PSV: Peak systolic velocity; RI: Resistive index; AJCC: American Joint Committee on Cancer

\section{Acknowledgments \\ Not Applicable.}

\section{Authors' contributions}

Conceived and designed the experiments: YF CP YZ LL. Performed the experiments: YF CP YZ LL. Analyzed the data: YF CP. Contributed reagents/ materials/analysis tools: YF CP YZ LL. Wrote the paper: YZ LL. Gave many suggestions in the formation of the manuscript: YZ LL. All authors have read and approved the manuscript.

\section{Funding}

This work was supported by a grant from the Natural Science Foundation of Zhejiang Province (No. LQ19H160003). The authors declare no support from any organisations for the submitted work. The design of the study, the analyses and the writing of the manuscript were solely the responsibility of the authors. The findings and conclusions in this manuscript are those of the authors and do not necessarily represent the views of Natural Science Foundation of Zhejiang Province.

\section{Availability of data and materials}

Our data can not be made publicly available for ethical reasons. Data are from the present study whose authors may be contacted at liuly@zjcc.org.cn or Department of Radiation Oncology, Zhejiang Cancer Hospital, Hangzhou, China.

\section{Ethics approval and consent to participate}

This study obtained approval from the Independent Ethics Committee of the Zhejiang Cancer Hospital (No. IRB-2020-15) to identify patients diagnosed with rectal cancer in our center. Because this was a retrospective study, consent was not obtained and patient records were anonymized and deidentified before analysis.

\section{Consent for publication}

Not applicable.

\section{Competing interests}

All authors declared no conflicts of interest.

\section{Author details}

'Institute of Cancer Research and Basic Medicine (ICBM), Chinese Academy of Sciences, No 1, East Banshan Road, Gongshu District, Hangzhou 310022, China. ${ }^{2}$ Department of Radiation Oncology, Cancer Hospital of the University of Chinese Academy of Sciences, No 1, East Banshan Road, Gongshu District, Hangzhou 310022, China. ${ }^{3}$ Department of Radiation Oncology, Zhejiang Cancer Hospital, No 1, East Banshan Road, Gongshu District, Hangzhou 310022, China. ${ }^{4}$ Department of Ultrasound, Cancer Hospital of the University of Chinese Academy of Sciences, No 1, East Banshan Road, Gongshu District, Hangzhou 310022, China. ${ }^{5}$ Department of Ultrasound, Zhejiang Cancer Hospital, No 1, East Banshan Road, Gongshu District, Hangzhou 310022, China.

Received: 13 May 2020 Accepted: 31 August 2020

Published online: 07 September 2020

\section{References}

1. Keller DS, Berho M, Perez RO, Wexner SD, Chand M. The multidisciplinary management of rectal cancer. Nat Rev Gastroenterol Hepatol. 2020;17(7): $414-29$

2. NCCN Guidelines Version 1. 2019. Available at: http://www.nccn.org/.

3. Chan BP, Patel R, Mbuagbaw L, Thabane L, Yaghoobi M. EUS versus magnetic resonance imaging in staging rectal adenocarcinoma: a diagnostic test accuracy meta-analysis. Gastrointest Endosc. 2019;90(2):196-203.
4. Ophir J, Céspedes I, Ponnekanti H, Yazdi Y, Li X. Elastography: a quantitative method for imaging the elasticity of biological tissues. Ultrason Imaging. 1991;13(2):111-34

5. Sigrist RMS, Liau J, Kaffas AE, Chammas MC, Willmann JK. Ultrasound elastography: review of techniques and clinical applications. Theranostics. 2017;7(5):1303-29.

6. Hunt D, Romero J. Contrast-enhanced ultrasound. Magn Reson Imaging Clin N Am. 2017;25(4):725-36.

7. Kitano M, Yamashita Y. New imaging techniques for endoscopic ultrasonography: contrast-enhanced endoscopic ultrasonography. Gastrointest Endosc Clin N Am. 2017;27(4):569-83.

8. Zhuang $H$, Yang $Z G$, Wang ZQ, Wang XD, Chen HJ, et al. Features of timeintensity curve parameters of colorectal adenocarcinomas evaluated by double-contrast enhanced ultrasonography: initial observation. Eur J Radiol. 2012;81(4):677-82

9. Waage JE, Bach SP, Pfeffer F, Leh S, Havre RF, Ødegaard S, et al. Combined endorectal ultrasonography and strain elastography for the staging of early rectal cancer. Color Dis. 2015;17(1):50-6.

10. Xiao Y, Xu D, Ju H, Yang C, Wang L, Wang J, et al. Application value of biplane transrectal ultrasonography plus ultrasonic elastosonography and contrastenhanced ultrasonography in preoperative T staging after neoadjuvant chemoradiotherapy for rectal cancer. Eur J Radiol. 2018:104:20-5.

11. Beynon J, Foy DM, Roe AM, Temple LN, Mortensen NJ. Endoluminal ultrasound in the assessment of local invasion in rectal cancer. Br J Surg. 1986;73(6):474-7.

12. Tombazzi CR, Loy P, Bondar V, Ruiz JI, Waters B, Tombazzi CR. Accuracy of endoscopic ultrasound in staging of early rectal cancer. Fed Pract. 2019; 36(Suppl 5):S26-9.

13. Ashraf S, Hompes R, Slater A, Lindsey I, Bach S, Mortensen NJ, et al. A critical appraisal of endorectal ultrasound and transanal endoscopic microsurgery and decision-making in early rectal cancer. Color Dis. 2012;14(7):821-6.

14. Ptok H, Marusch F, Meyer F, Wendling P, Wenisch HJ, Sendt W, et al. Feasibility and accuracy of TRUS in the pre-treatment staging for rectal carcinoma in general practice. Eur J Surg Oncol. 2006;32(4):420-5.

15. Marusch F, Ptok H, Sahm M, Schmidt U, Ridwelski K, Gastinger I, et al. Endorectal ultrasound in rectal carcinoma--do the literature results really correspond to the realities of routine clinical care? Endoscopy. 2011;43(5):425-31.

16. Heneghan JP, Salem RR, Lange RC, Taylor KJ, Hammers LW. Transrectal sonography in staging rectal carcinoma: the role of gray-scale, color-flow, and Doppler imaging analysis. AJR Am J Roentgenol. 1997;169(5):1247-52.

17. Zhang M, Tang J, Luo Y, Wang Y, Wu M, Memmott B, et al. Diagnostic performance of multiparametric transrectal ultrasound in localized prostate cancer: a comparative study with magnetic resonance imaging. J Ultrasound Med. 2019;38(7):1823-30.

18. Zheng W, Chen K, Peng C, Yin SH, Pan YY, Liu M, et al. Contrast-enhanced ultrasonography vs MRI for evaluation of local invasion by cervical cancer. Br J Radiol. 2018;91(1091):20170858.

19. Zhang B, Sun Z, Song M, Ma S, Tian Y, Kong Q. Ultrasound/CT combined with serum CEA/CA19.9 in the diagnosis and prognosis of rectal cancer. J BUON. 2018:23(3):592-7.

20. Chen LD, Liang JY, Wu H, Wang Z, Li SR, Li W, et al. Multiparametric radiomics improve prediction of lymph node metastasis of rectal cancer compared with conventional radiomics. Life Sci. 2018;208:55-63.

\section{Publisher's Note}

Springer Nature remains neutral with regard to jurisdictional claims in published maps and institutional affiliations.

Ready to submit your research? Choose BMC and benefit from:

- fast, convenient online submission

- thorough peer review by experienced researchers in your field

- rapid publication on acceptance

- support for research data, including large and complex data types

- gold Open Access which fosters wider collaboration and increased citations

- maximum visibility for your research: over $100 \mathrm{M}$ website views per year

At $\mathrm{BMC}$, research is always in progress.

Learn more biomedcentral.com/submissions 